\title{
Regenerative Medicine in an Elite Football Athlete: A Case Report
}

\begin{abstract}
Matias Cristian Fernández Viña $a^{1,2,3,4 *}$ and Camozzi Liliana ${ }^{3,4}$
${ }^{1}$ Facultad de Medicina y Cs. de la Salud. Universidad Abierta Interamericana, Rosario, Argentina
\end{abstract}

2REGENERóN by Stem Cell Therapy Argentina, San Nicolás de los Arroyos, Argentina

${ }^{3}$ Fundación Don Roberto Fernández Viña, San Nicolás, Argentina

${ }^{4}$ Clínica San Nicolás S.A, San Nicolás, Argentina

\begin{abstract}
Osteoarthritis $(O A)$ is a degenerative disorder resulting from loss of joint cartilage and underlying bone. Sports injuries are considered disorders of the musculoskeletal system or concussions that are generally caused during sportive activities such as football. Blood-derived products, especially Platelet- Rich Plasma (PRP), aims to improve the process of tissue repair through the delivery of growth factors that provide chemotactic, proliferative and anabolic responses.

We present a case report of a Football First Division Athlete, 24 years old, with no hierarchical antecedents, suffered on January 2020, a sports traumatic impact on the right knee, generating an osteochondral injury with an unstable appearance due to the manifestation of a focus of cartilage and bone between two hypointense signal sheets in Resonance Magnetic T1. In turn, inflammatory patterns were evident in the internal lateral ligament and the anterior cruciate ligament. The patient underwent Platelet Rich Plasma (PRP) therapy at the department of REGENERóN Regenerative Medicine Institute by Stem Cell Therapy Argentina. This procedure has been shown to be effective and safe for chondral injuries like we can see on this case report.
\end{abstract}

*Corresponding author: Matias Cristian Fernández Viña, Facultad de Medicina y Cs. de la Salud. Universidad Abierta Interamericana, Rosario, Argentina; REGENERóN by Stem Cell Therapy Argentina, San Nicolás, Argentina; Fundación Don Roberto Fernández Viña, San Nicolás, Argentina; Clínica San Nicolás S.A, Argentina, E-mail: Matias.FernandezVina@UAl.edu.ar

Citation: Viña MCF, Liliana C (2020) Regenerative Medicine in an Elite Football Athlete: A Case Report. J Stem Cell Res Dev Ther 6: 059.

Received: December 14, 2020; Accepted: December 17, 2020; Published: December 23, 2020

Copyright: () 2020 Viña MCF, et al. This is an open-access article distributed under the terms of the Creative Commons Attribution License, which permits unrestricted use, distribution, and reproduction in any medium, provided the original author and source are credited.

\section{Introduction}

Osteoarthritis (OA) is a degenerative disorder resulting from loss of joint cartilage and underlying bone [1]. Articular cartilage is an avascular connective tissue and serves as a buffer material to weightbearing and shearing forces together with the unique extracellular matrix, which is composed of high concentration of proteoglycans, polymeric Hyaluronic Acid (HA), and link protein. Under stimulation with repetitive mechanical injury, the elevated inflammatory cytokines, produced by fibroblast-like synovial cells, macrophage-like synovial cells, and chondrocytes such as interleukin (IL) 1 and tumor necrosis factor alpha result in a significant effect of cartilage damage [1]. There are no approved disease modification therapies for OA, and the only non-invasive pharmacologic therapies recommended for OA symptom management are analgesics and Non-Steroidal Anti-Inflammatory Drugs (NSAIDs) [2,3]. Intra-articular therapies, including corticosteroids and Hyaluronic Acid (HA) are frequently used to treat knee OA, but both treatments have limitations. The American Academy of Orthopaedic Surgeons (AAOS) determined that there was inconclusive evidence to support the use of intraarticular corticosteroids of OA [4] and several recent studies have suggested that corticosteroids may have detrimental catabolic effects on cartilage $[5,6]$.

Recently, cell-based therapies have emerged as possible diseasemodifying treatments. Mesenchymal Stem Cells (MSCs) Platelatel Rich Plasma, Adipose-derived Stem Cells (ASCs) have demonstrated chondrogenic potential [7].

Sports injuries are considered disorders of the musculoskeletal system or concussions [8] that are generally caused during sportive activities such as football.

The most common injuries related to the sport are acute muscle tears (involving hamstrings, adductors, and calf muscles) and muscle strains $[9,10]$, being acute hamstring injuries have one of the highest recurrence rates that can lead to prolonged absence from sports $[11,12]$. In football, for example, 25 players in the squad have approximately five hamstring injuries each season, equivalent to more than 80 lost football days [9].

Blood-derived products, especially Platelet- Rich Plasma (PRP) [11], aim to improve the process of tissue repair through the delivery of growth factors that provide chemotactic, proliferative and anabolic responses $[12,13]$. This product has grown in popularity over the past few years in several fields of medicine, including aesthetics [14], dentistry [15], autoimmune disease [16] and orthopedics [17]. Despite the widespread unregulated use, the efficacy of PRP therapy has yet to be established $[18,19]$.

\section{Case Presentation}

A 24-year-old male with no previous history of trauma or knee surgery visited our Regenerative Medicine Institute REGENERóN in January 2020. His body weight was $65 \mathrm{~kg}$ and height was $170 \mathrm{~cm}$ 
(Body Mass Index [BMI]: $22.5 \mathrm{~kg} / \mathrm{m}^{2}$ ). He complained of knee pain and painful sensation over right knee during walking after impactation trauma. The KOOS was 50 points in resting. Poor walking endurance and soreness were also noted in the daytime.

\section{Materials and Methods}

The author obtained written consent of the patient to describe the illness and publish this case report.

Football First Division Athlete, 24 years old, with no hierarchical antecedents, suffered on January 2020, a sports traumatic impact on the right knee, generating an osteochondral injury with an unstable appearance due to the manifestation of a focus of cartilage and bone between two hypointense signal sheets in Resonance Magnetic T1. In turn, inflammatory patterns were evident in the internal lateral ligament and the anterior cruciate ligament (Figure 1).

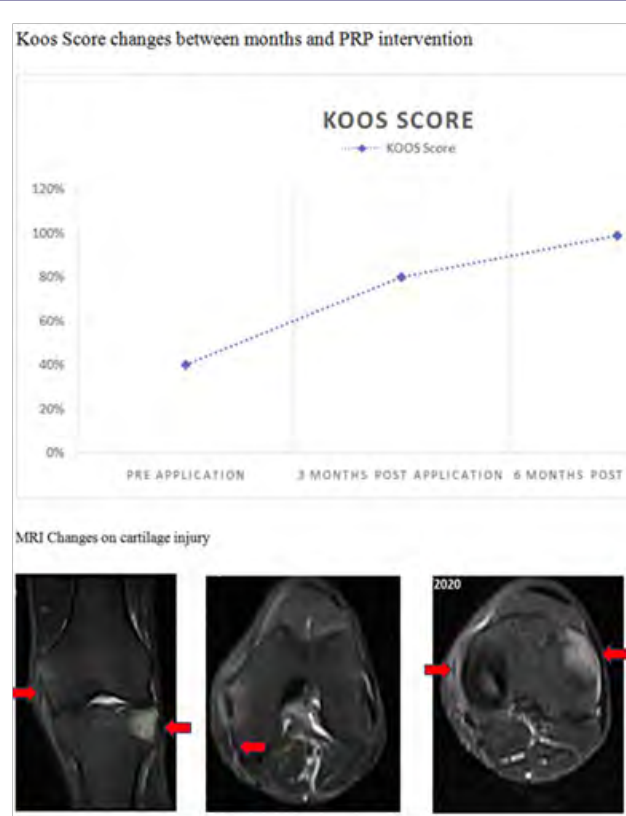

Figure 1: The internal collateral ligament manifests a surrounding hyper intensity compatible with Peri-ligamentous edema, without alterations in signal intensity or intraligamentary thickness associated with soft tissue edema. External tibial plateau with stable osteochondral lesion, with adjacent area of bone edema. Discrete increase in synovial fluid in the sub-quadriceps bursa and in the interline femoro-tibial. The femoro patellar joint is of normal characteristics. The patellar and quadriceps tendons are of normal morphology and signal intensity. The cruciate ligaments, the external collateral ligament and the iliotibial band are of morphology, path and normal intensity. Both menisci are of normal morphology and signal intensity, preserving their articular surfaces. Muscle structures are of normal morphology.

The patient underwent Platelet Rich Plasma (PRP) therapy at the department of REGENERóN Regenerative Medicine Institute by Stem Cell Therapy Argentina.

The extraction of $51 \mathrm{ml}$ of blood was carried out aseptically using the closed vacuum system with sterile tubes for humans (BD) with ACD Solution A. Centrifugation was performed for 48 minutes (according to the Stem Cell Therapy Argentina ${ }^{\circledR}$, private protocol) to obtain a high PRP concentration or high platelet concentrated (HPC Registered) product through a Thermo Fisher Scientific refrigerated centrifuge. The gradient centrifugation was performed under Good Laboratory Practices (GMP) by a physician trained in Advanced Therapies and Regenerative Medicine, in order to obtain an average concentration of $2858 \times 10$ [9] platelets/L by using a Thermo Fisher Scientific laminar flow and positive pressure High Efficiency Particulate Air (HEPA) filtered system. Prior to the injection of HPC, a quality control of the process and the product was performed through a Wiener Lab Counter 19 hematology analyzer (Figure 2).

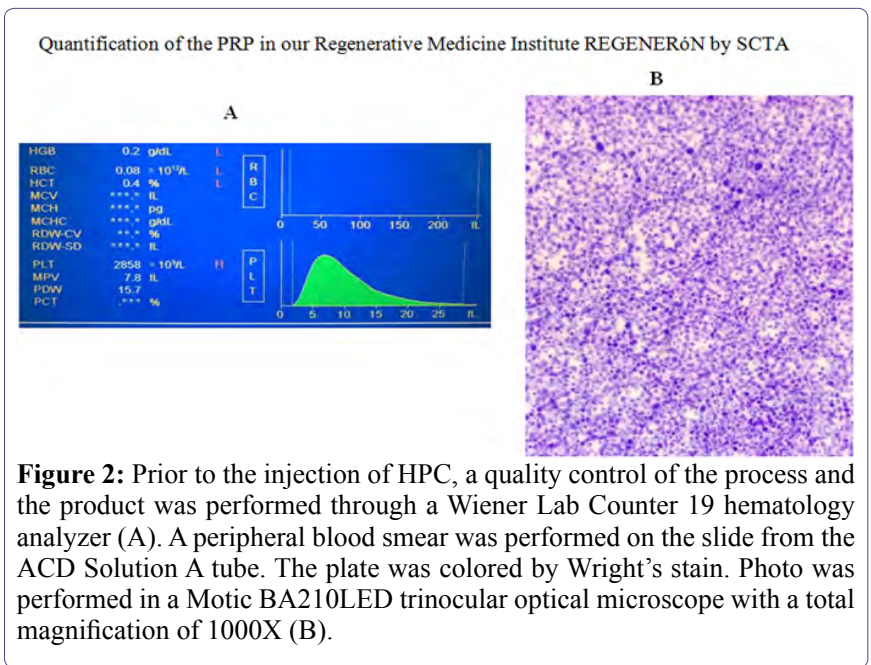

An amount of $3 \mathrm{cc}$ of HPC was drawn aseptically into $3 \mathrm{cc}$ sterile syringe. Subsequently, the patient was injected the product intraarticularly.

One functional index evaluated for the quality of life was the Knee Injury and Osteoarthritis Outcome Score (KOOS) was used to evaluate the patient clinical symptoms.

The Knee injury and Osteoarthritis Outcome Score (KOOS) was developed as an extension of the WOMAC Osteoarthritis Index with the purpose of evaluating short-term and long-term symptoms and function in subjects with knee injury and osteoarthritis. The KOOS holds five separately scored subscales: Pain, other Symptoms, Function in daily living (ADL), Function in Sport and Recreation (Sport/Rec), and knee-related Quality of Life (QOL). The KOOS has been validated for several orthopedic interventions such as anterior cruciate ligament reconstruction, meniscectomy and total knee replacement. In addition, the instrument has been used to evaluate physical therapy, nutritional supplementation and glucosamine supplementation. The KOOS is a knee-specific instrument, developed to assess the patients' opinion about their knee and associated problems.

Magnetic Resonance (MRI) study was carried out before first HPC application and 4 months after (Figure 3).

\section{Results}

- Previous application of HPC, the patient completes the KOOS Score, that was $40 \%$

- We injected $3 \mathrm{ml}$ of HPC intraarticular by live fluoroscopy

- After 3 months, the KOOS was improved to $80 \%$, and on the 4 month, MRI changes could be evaluated (Figure 3)

- After 6 months, the KOOS score was $99 \%$ 


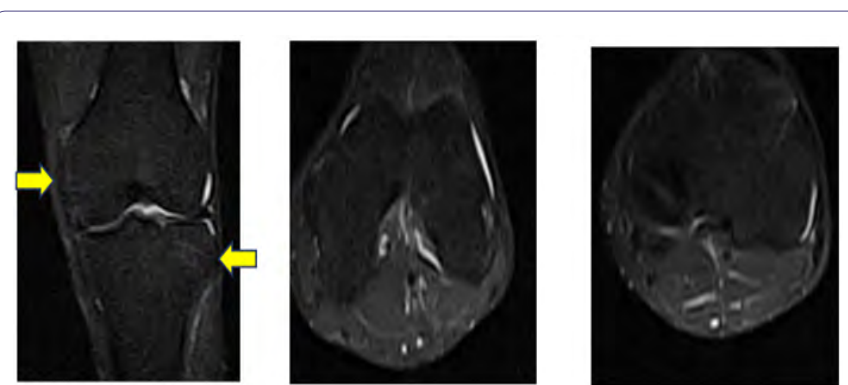

Figure 3: The femoro-patellar joint is of normal characteristics. The patellar and quadriceps tendons are of normal morphology and signal intensity. The cruciate ligaments, the external collateral ligament and the iliotibial band are of morphology, path and normal intensity. Both menisci are of normal morphology and signal intensity, preserving their articular surfaces. Muscle structures are of normal morphology.

\section{Discussion}

Regenerative biomedicine is progressively emerging at the forefront of medicine. This innovative field includes interventions such as the use of Platelet-Rich Plasma (PRP), mesenchymal stem cells, extracorporeal shock wave treatment, sclerosing agents, nitric oxide, and matrix metalloproteinase [19].

In this case report we will focus on PRP, a bioactive regenerative therapy that has garnered significant attention in recent years. Results of animal studies have demonstrated the efficacy of PRP in accelerating the healing process after muscle [20], ligament [20], joint [21], and tendon [22,23] injuries. Human clinical trials are emerging alongside numerous anecdotal cases that demonstrate the promise of this innovative therapy, which likely will play a major role in shaping the landscape of sports medicine [19,24].

The management of chondral injury/pathology present a challenge to clinicians. The natural history of chondral defects is not well documented and although many studies indicate that they are progressive and lead to development of osteoarthritis, others are less conclusive. It is likely that progression is dependent upon variables such as patient's sex, age, weight, size and depth of lesion and also mechanism of injury.Current surgical management of traumatic and/or degenerative chondral lesions includes arthroscopic chondroplasty, microfracture/osteoplasty and when appropriate autologous chondrocyte implantation or Matrix Induced Autologous Chondrocyte Implantation (MACI) [25].

A case report described a 12-year-old soccer player with knee pain and Magnetic Resonance Imaging (MRI) findings of a large chondral lesion in his medial femoral condyle. He had a $2 \mathrm{~cm}$ loose chondral body in the intercondylar fossa and underwent PRP-supplemented arthroscopic surgery to reattach the loose body, with resultant good functional outcome [26].

In the animal literature, results of several studies demonstrated evidence of osteogenesis and formation of cartilaginous tissue with PRP combined with chondrocytes or a collagen matrix [27]. Sustained-release PRP intra-articular injections also resulted in increased cartilage matrix metabolism [27]. Although chondrocytes and PRP appeared to stimulate chondrogenesis subcutaneously, demineralizedbone matrix and PRP did not stimulate osteogenesis intra- muscularly [27], which prompts further questions about the substrates with which PRP may have synergistic effects and the environment in which the composite is placed [27].
Platelets are 'small, non-nucleated bodies, produced by megakaryocytes in the bone marrow that circulate in peripheral blood and are known primarily for their role in hemostasis' [27].

Intraarticularly injected sustained release vehicles for PRP appeared to stimulate cartilage matrix metabolism, which suggests potential uses in osteoarthritis management $[28,29]$.

By definition, PRP must contain a higher concentration of platelets than baseline $[10,13]$, however, there are many other variables in the make-up of PRP that will lead to different biologic and physiologic properties; and possibly effective- ness. An increase in platelets is an incomplete and simplistic description of PRP. There are multiple parameters in addition to platelet concentration which should be considered.PRP preparation is a simple, low-cost and minimally invasive procedure that provides a natural concentrate of autologous haemopoietically derived growth factors that can assist musculoskeletal tissue repair [10].

As you can see, the PRP has been given a special treatment as it is not an advanced therapy product; the cells are not stem cells. This is a frequently seen news headline every time one of our colleagues applies it to an athlete, with the damage this does to the good use of the medicine. Responsibility for the poor information that is transmitted to the public in general when "to sell more" we give out this kind of information is ours and only ours. Not only when it is released in the press, but also when we are capable of marketing the product as if it were a "magic potion", able to "cure" all kinds of illnesses and which can be applied whenever necessary. The majority of times without much scientific evidence. We should be clear that as it is a medicine, this type of publicity is not allowed. Our obligation as professionals is to comply rigorously with the existing legislation, the base of the Good Clinical Practices that should define professionals in the clinical practice in general [30].

The use of PRP to stimulate cartilage repair is a particularly exciting application. Osteoarthritis represents a large burden on quality of life, productivity, and health care costs and its incidence is forecast to rise considerably over the next decade. It is thought that PRP can stimulate chondral anabolism, reduce catabolic processes, and may improve overall joint homeostasis reducing synovial membrane hyperplasia [31]. The work of Mishra et al., supports this demonstrating that PRP stimulates mesenchymal stem cell proliferation in vitro [32].

Kon et al., injected PRP into 115 knees with documented degeneration. Significant improvement of all clinical scores was found at 6-12 months compared to baseline $(\mathrm{p}<0.0005)$. They found PRP injections to be safe and had the potential to reduce pain and improve knee function [33]. This data may help support the use of PRP to treat athletes with early degenerative changes.

In sports medicine, athletes and the media will continue to drive the use of platelet rich plasma as a treatment for a plethora of acute and chronic problems. In the long run, prospective, randomized trials will supplant anecdotal results and help clinicians develop specific treatment guidelines. It will be crucial as this evidence evolves to demand reporting of the type of PRP used, the rehabilitation process and objective outcome measurements whenever possible [34].

Recently, Kon et al published a prospective clinical study comparing the efficacy of PRP injections compared with HA injections for the treatment of cartilage degenerative lesions and OA. 
In this study, 50 patients received 3 autologous PRP injections every 2 weeks, 50 patients received high-molecular-weight HA injections, and 50 patients received low-molecular-weight HA injections. The authors used 2-month and 6-month end points and found that overall, at 6 months after therapy; improved results were seen in the PRP group with regard to pain and symptom control. The authors did report worse outcomes in patients who were older with more advanced arthritis [34].

In one of the larger cohort studies available, Sanchez et alreported on a prospective group of 60 patients with knee pain receiving either PRP or Hyaluronic Acid (HA) injections weekly for 3 weeks. Although this study did not specifically focus on the treatment of isolated chondral defects, this was one of the first comparison studies published describing the clinical effects of PRP therapy. Overall, the PRP group had statistically significantly improved pain scores, function scores, and overall Western Ontario and McMaster Universities Arthritis Index (WOMAC) scores when compared with the HA group [35].

Patel et al performed a double-blind randomized controlled trial investigating the effect of PRP versus saline injections in patients with early osteoarthritis of the knee. A total of 156 knees were divided into 3 groups: saline control group, a single injection of PRP, and 2 injections of PRP 3 weeks apart. White blood cell-filtered PRP with a concentration of platelets 3 baseline was used. The authors reported significantly improved WOMAC scores over baseline in both PRP groups at all time points during the 6-month follow-up [36].

Several studies in literature report that growth factors contained in PRP promote chondrocytes synthesis through regulation of gene expression, proteoglycans production and type II collagen deposition $[37,38]$. Platelet-rich plasma has a high concentration of platelets that once implanted release in the site important growth factors such as the platelet-derived growth factor, the Transforming Growth Factor- $\beta$ (TGF- $\beta$ ), the fibroblast growth factor, the Insulin like Growth Factor (IGF-1 and IGF-2) and the vascular endothelial growth factor. Among these, the TGF- $\beta$ seems to play a key-role to support and enhance other growth factors [39]

Growth factors play an important role in maintaining the cartilage tissue and joint structures homeostasis as a whole $[40,41]$ and thanks to their interaction they give a contribution to the increasing of chondral phenotype cells expression and proliferation, they stimulate the mesenchymal stem cells differentiation in a chondrogenic sense, they promote the matrix deposition and slow down the matrix catabolism, and they reduce the suppressive effect exerted by the inflammatory mediators on the proteoglycans synthesis [40].

\section{Conclusion}

Chondral defects treatment can now rely on a different regenerative product like PRP, which aim at promoting the restoration of the joint surface based on a biological approach. PRP has been around for approximately 15 to 20 years but the technique of administration has improved greatly and supportive research has emerged recently. This involves taking the patient's own blood and spinning it down in a centrifuge to produce a medium rich in platelets and growth factors that stimulate healing when injected into injured areas. The main problem we are presenting is the lack of standardization of PRP.
The involved portions of joints and tendons have poor blood flow, which is felt to be the cause of poor spontaneous healing. The goal of the PRP application is to stimulate a better healing environment. PRP has been used in cartilage to treat osteoarthritis and to support treatment techniques for chondral injuries. This procedure has been shown to be effective and safe for chondral injuries like we can see on this case report.Future prospective randomized controlled trials are warranted to conclusively ascertain the longterm safety and efficacy of the use of PRP on this type of injuries on Sport Medicine.

\section{Disclosure}

No commercial party having a direct financial interest in the results of the research supporting this article has or will confer a benefit upon the authors or upon any organization with which the authors are associated. The authors report no conflicts of interest in this work.

\section{Funding}

This work was funded by Fundación Don Roberto Fernández Viña.

\section{Acknowledgments}

Thanks to Dr. Diego Correa, Milena Gomez Cuesta, Carolina Quintero Gil, Karolynn Harpert and Santiago Salvarriaga for their contribution.

Thanks to Universidad Abierta Interamericana, REGENERóN Regenerative Medicine Institute by Stem Cell Therapy Argentina, Instituto de Terapias Avanzadas Colombia, and BioX cellerator Colombia and Fundación Don Roberto Fernandez Viña.

\section{References}

1. Martel-Pelletier J, Boileau C, Pelletier JP, Roughley PJ (2008) Cartilage in normal and osteoarthritis conditions. Best Pract Res Clin Rheumatol 22: $351-384$.

2. Brown GA (2013) AAOS clinical practice guideline: treatment of osteoarthritis of the knee: evidence-based guideline, 2nd edition. J Am Acad Orthop Surg 21: 577-579.

3. Maniar KH, Jones IA, Gopalakrishna R, Vangsness CT Jr (2018) Lowering side effects of NSAID usage in osteoarthritis: recent attempts at minimizing dosage. Expert Opin Pharmacother 19: 93-102.

4. Jevsevar DS (2013) Treatment of osteoarthritis of the knee: evidence-based guideline, 2nd edition. J Am Acad Orthop Surg 21: 571-576.

5. McAlindon TE, LaValley MP, Harvey WF, Price LL, Driban JB, et al. (2017) Effect of intra-articular triamcinolone vs saline on knee cartilage volume and pain in patients with knee osteoarthritis: a randomized clinical trial. JAMA 317: 1967-1975.

6. Wernecke C, Braun HJ, Dragoo JL (2015) The Effect of Intra-articular Corticosteroids on Articular Cartilage: A Systematic Review. Orthop J Sports Med 3: 2325967115581163.

7. Coughlin RP, Oldweiler A, Mickelson DT, Moorman CT III (2017) Adipose- derived stem cell transplant technique for degenerative joint disease. Arthrosc Tech 6: 1761-1766.

8. Clarsen B, Rønsen O, Myklebust G, Flørenes TW, Bahr R (2014) The Oslo sports trauma research center questionnaire on health problems: A new approach to prospective monitoring of illness and injury in elite athletes. Br J Sports Med 48: 2014.

9. Ekstrand J, Hagglund M, Walden M (2011) Epidemiology of muscle injuries in professional football (soccer). Am J Sports Med 39: 1226-1232. 
10. Jarvinen TAH, Jarvinen TLN, Kaariainen M, Kalimo H, Järvinen M (2005) Muscle injuries: Biology and treatment. Am J Sports Med 33: 745-764.

11. Askling CM, Tengvar M, Saartok T, Thorstensson A (2007) Acute firsttime hamstring strains during high- speed running: A longitudinal study including clinical and magnetic resonance imaging findings. Am J Sports Med 35: 197- 206

12. Ekstrand J, Healy JC, Waldén M, Lee JC, English B, et al. (2012) Hamstring muscle injuries in professional football: The correlation of MRI findings with return to play. Br J Sports Med 46: 112- 117.

13. Hamid MSA, Yusof A, Ali MRM (2014) Platelet-rich plasma (PRP) for acute muscle injury: A systematic review. PLoS One 9: 90538.

14. Marx RE (2001) Platelet-rich plasma (PRP): what is PRP and what is not PRP? Implant Dent 10: 225-228.

15. Marx RE, Carlson ER, Eichstaedt RM, Schimmele SR, Strauss JE, et al (1998) Platelet-rich plasma: Growth factor enhancement for bone grafts. Oral Surg Oral Med Oral Pathol Oral Radiol Endod 85: 638-646.

16. Rodrigues BL, Montalvao SA, Cancela RBB, Silva FAR, Urban A, et al. (2019) Treatment of male pattern alopecia with platelet-rich plasma: a double blind controlled study with analysis of platelet number and growth factor levels. J Am Acad Dermatol 80: 694-700.

17. Zotti F, Albanese M, Rodella LF, Nocini PF (2019) Platelet-rich plasma in treatment of temporomandibular joint dysfunctions: Narrative review. Int J Mol Sci 20: 277.

18. Filardo G, Kon E, Buda R, Timoncini A, Martino AD, et al. (2011) Platelet-rich plasma intra-articular knee injections for the treatment of degenerative cartilage lesions and osteoarthritis. Knee Surg Sports Traumatol Arthrosc 19: 528-535.

19. Nguyen RT, Borg-Stein J, McInnis K (2011) Applications of Platelet-Rich Plasma in Musculoskeletal and Sports Medicine: An Evidence-Based Approach. PM R 3: 226-250.

20. Hammond JW, Hinton RY, Curl LA, Muriel JM, Lovering RM (2009) Use of autologous platelet-rich plasma to treat muscle strain injuries. Am J Sports Med 37: 1135-1142.

21. Hildebrand KA, Woo SL, Smith DW, Allen CR, Deie M, et al. (1998) The effects of platelet-derived growth factor-BB on healing of the rabbit medial collateral ligament. An in vivo study. Am J Sports Med 26: 549-554.

22. Saito M, Takahashi KA, Arai Y, Inoue A, Sakao K, et al. (2009) Intraarticular administration of platelet-rich plasma with biodegradable gelatin hydrogel microspheres prevents osteoarthritis progression in the rabbit knee. Clin Exp Rheumatol 27: 201-207.

23. Lyras DN, Kazakos K, Verettas D, Botaitis S, Agrogiannis G, et al. (2009) The effect of platelet-rich plasma gel in the early phase of patellar tendon healing. Arch Orthop Trauma Surg 129: 1577-1582.

24. Virchenko O, Aspenberg P (2006) How can one platelet injection after tendon injury lead to a stronger tendon after 4 weeks? Interplay between early regeneration and mechanical stimulation. Acta Orthop 77: 806-812.

25. Freitag J, Barnard A, Rotstein A (2012) Photoactivated platelet-rich plasma therapy for a traumatic knee chondral lesion. BMJ Case Reports: 006858.

26. Sanchez M, Azofra J, Anitua E, Andía I, Padilla S, et al. (2003) Plasma rich in growth factors to treat an articular cartilage avulsion: A case report. Med Sci Sports Exerc 35: 1648-1652.
27. Foster TE, Puskas BL, Mandelbaum BR, Gerhardt MB, Rodeo SA (2017) Platelet-Rich Plasma: From Basic Science to Clinical Application. Am J Sports Med 37: 2259-2272.

28. Qi YY, Chen X, Jiang YZ, Cai HX, Wang LL, et al. (2009) Local delivery of autologous platelet in collagen matrix stimulated in-situ articular cartilage repair. Cell Transplant 18: 1161-1169.

29. Saito M, Takahashi KA, Arai Y, Inoue A, Sakao K, et al. (2009) Intraarticular administration of platelet-rich plasma with biodegradable gelatin hydrogel micro- spheres prevents osteoarthritis progression in the rabbit knee. Clin Exp Rheumatol 27: 201-207.

30. Cárceles JN, Santos MEF (2016) Good Clinical Practice in the use of regenerative medicine in athletes, Arch Med Deporte 33: 302-304.

31. Kon E, Filardo G, Delcogliano M, Presti ML, Russo A, et al. (2009) Platelet-rich plasma: new clinical application: A pilot study for treatment of jumper's knee. Injury 40: 598-603.

32. Mishra A, Tummala P, King A, Lee B, Kraus M, et al. (2009) Buffered platelet-rich plasma enhances mesenchymal stem cell proliferation and chondrogenic differentiation. Tissue Engineering Part C Methods 15: 431435 .

33. Kon E, Mandelbaum B, Buda R, Filardo G, Delcogliano M, et al. (2011) Platelet-rich plasma intra-articular injection versus hyaluronic acid viscosupplementation as treatments for cartilage pathology: from early degeneration to osteoarthritis. Arthroscopy 27: 1490-1501.

34. Kon E, Buda R, Filardo G, Di Martino A, Timoncini A, et al. (2010) Platelet- rich plasma: Intra-articular knee injections produced favorable results on degenerative cartilage lesions. Knee Surg Sports Traumatol Arthrosc 18: 472-479.

35. Sanchez M, Anitua E, Azofra J, Aguirre JJ, Andia I (2008) Intra-articular injection of an autologous preparation rich in growth factors for the treatment of knee OA: A retrospective cohort study. Clin Exp Rheumatol 26: 910-913.

36. Patel S, Dhillon MS, Aggarwal S, Marwaha N, Jain A (2013) Treatment with platelet-rich plasma is more effective than placebo for knee osteoarthritis: A prospective, double-blind, randomized trial. Am J Sports Med 41: 356-364.

37. Akeda K, An HS, Okuma M, Attawia M, Miyamoto K (2006) Platelet-rich plasma stimulates porcine articular chondrocyte proliferation and matrix biosynthesis. Osteoarthr Cartilage 14: 1272-1280.

38. Wu W, Chen F, Liu Y, Ma Q, Mao T (2007) Autologous injectable tissue-engineered cartilage by using platelet-rich plasma: experimental study in a rabbit model. J Oral Maxil Surg 65: 1951-1957.

39. Hammond JW, Hinton RY, Curl LA, Muriel JM, Lovering RM (2009) Use of autologous platelet- rich plasma to treat muscle strain injuries. Am J Sport Med 37: 1135-1142.

40. Frazer A, Bunning RA, Thavarajah M, Seid JM, Russell RG (1994) Studies on type II collagen and aggrecan production in human articular chondrocytes in vitro and effects of transforming growth factor-beta and interleukin-1beta. Osteoarthr Cartilage 2: 235-45.

41. Schmidt MB, Chen EH, Lynch SE (2006) A review of the effects of insulin- like growth factor and platelet derived growth factor on in vivo cartilage healing and repair. Osteoarthr Cartilage 14: 403-412. 


\section{di

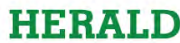

Advances In Industrial Biotechnology | ISSN: 2639-5665

Advances In Microbiology Research | ISSN: 2689-694X

Archives Of Surgery And Surgical Education | ISSN: 2689-3126

Archives Of Urology

Archives Of Zoological Studies | ISSN: 2640-7779

Current Trends Medical And Biological Engineering

International Journal Of Case Reports And Therapeutic Studies | ISSN: 2689-310X

Journal Of Addiction \& Addictive Disorders | ISSN: 2578-7276

Journal Of Agronomy \& Agricultural Science | ISSN: 2689-8292

Journal Of AIDS Clinical Research \& STDs | ISSN: 2572-7370

Journal Of Alcoholism Drug Abuse \& Substance Dependence | ISSN: 2572-9594

Journal Of Allergy Disorders \& Therapy | ISSN: 2470-749X

Journal Of Alternative Complementary \& Integrative Medicine | ISSN: 2470-7562

Journal Of Alzheimers \& Neurodegenerative Diseases | ISSN: 2572-9608

Journal Of Anesthesia \& Clinical Care | ISSN: 2378-8879

Journal Of Angiology \& Vascular Surgery | ISSN: 2572-7397

Journal Of Animal Research \& Veterinary Science | ISSN: 2639-375

Journal Of Aquaculture \& Fisheries | ISSN: 2576-5523

Journal Of Atmospheric \& Earth Sciences | ISSN: 2689-8780

Journal Of Biotech Research \& Biochemistry

Journal Of Brain \& Neuroscience Research

Journal Of Cancer Biology \& Treatment | ISSN: 2470-7546

Journal Of Cardiology Study \& Research | ISSN: 2640-768X

Journal Of Cell Biology \& Cell Metabolism | ISSN: 2381-1943

Journal Of Clinical Dermatology \& Therapy | ISSN: 2378-8771

Journal Of Clinical Immunology \& Immunotherapy | ISSN: 2378-8844

Journal Of Clinical Studies \& Medical Case Reports | ISSN: 2378-8801

Journal Of Community Medicine \& Public Health Care | ISSN: 2381-1978

Journal Of Cytology \& Tissue Biology | ISSN: 2378-9107

Journal Of Dairy Research \& Technology | ISSN: 2688-9315

Journal Of Dentistry Oral Health \& Cosmesis | ISSN: 2473-6783

Journal Of Diabetes \& Metabolic Disorders | ISSN: 2381-201X

Journal Of Emergency Medicine Trauma \& Surgical Care | ISSN: 2378-8798

Journal Of Environmental Science Current Research | ISSN: 2643-5020

Journal Of Food Science \& Nutrition | ISSN: 2470-1076

Journal Of Forensic Legal \& Investigative Sciences | ISSN: 2473-733X

Journal Of Gastroenterology \& Hepatology Research | ISSN: 2574-2566
Journal Of Genetics \& Genomic Sciences | ISSN: 2574-2485

Journal Of Gerontology \& Geriatric Medicine | ISSN: 2381-8662

Journal Of Hematology Blood Transfusion \& Disorders | ISSN: 2572-2999

Journal Of Hospice \& Palliative Medical Care

Journal Of Human Endocrinology | ISSN: 2572-9640

Journal Of Infectious \& Non Infectious Diseases | ISSN: 2381-8654

Journal Of Internal Medicine \& Primary Healthcare | ISSN: 2574-2493

Journal Of Light \& Laser Current Trends

Journal Of Medicine Study \& Research | ISSN: 2639-5657

Journal Of Modern Chemical Sciences

Journal Of Nanotechnology Nanomedicine \& Nanobiotechnology | ISSN: 2381-2044

Journal Of Neonatology \& Clinical Pediatrics | ISSN: 2378-878X

Journal Of Nephrology \& Renal Therapy | ISSN: 2473-7313

Journal Of Non Invasive Vascular Investigation | ISSN: 2572-7400

Journal Of Nuclear Medicine Radiology \& Radiation Therapy | ISSN: 2572-7419

Journal Of Obesity \& Weight Loss | ISSN: 2473-7372

Journal Of Ophthalmology \& Clinical Research | ISSN: 2378-8887

Journal Of Orthopedic Research \& Physiotherapy | ISSN: 2381-2052

Journal Of Otolaryngology Head \& Neck Surgery | ISSN: 2573-010X

Journal Of Pathology Clinical \& Medical Research

Journal Of Pharmacology Pharmaceutics \& Pharmacovigilance | ISSN: 2639-5649

Journal Of Physical Medicine Rehabilitation \& Disabilities | ISSN: 2381-8670

Journal Of Plant Science Current Research | ISSN: 2639-3743

Journal Of Practical \& Professional Nursing | ISSN: 2639-568

Journal Of Protein Research \& Bioinformatics

Journal Of Psychiatry Depression \& Anxiety | ISSN: 2573-0150

Journal Of Pulmonary Medicine \& Respiratory Research | ISSN: 2573-0177

Journal Of Reproductive Medicine Gynaecology \& Obstetrics | ISSN: 2574-2574

Journal Of Stem Cells Research Development \& Therapy | ISSN: 2381-2060

Journal Of Surgery Current Trends \& Innovations | ISSN: 2578-7284

Journal Of Toxicology Current Research | ISSN: 2639-3735

Journal Of Translational Science And Research

Journal Of Vaccines Research \& Vaccination | ISSN: 2573-0193

Journal Of Virology \& Antivirals

Sports Medicine And Injury Care Journal | ISSN: 2689-8829

Trends In Anatomy \& Physiology | ISSN: 2640-7752

Submit Your Manuscript: https://www.heraldopenaccess.us/submit-manuscript 